\title{
Anxiety, Depression, and Cardiac Outcomes after a first Acute Coronary
}

\section{Syndrome}

Paolo Ossola ${ }^{\mathrm{a}}$, Maria Lidia Gerra ${ }^{\mathrm{b}}$, Chiara De Panfilis ${ }^{\mathrm{a}}$, Matteo Tonna ${ }^{\mathrm{b}}$, Carlo Marchesi ${ }^{\mathrm{a}}$.

a Psychiatry Unit, Department of Medicine and Surgery, Università degli Studi di Parma, Parma, Italy;

paolo.ossola@unipr.it; marialidia.gerra@studenti.unipr.it; chiara.depanfilis@unipr.it; carlo.marchesi@unipr.it

${ }^{\mathrm{b}}$ Department of Mental Health, AUSL Parma, Parma, Italy.

; mtonna@ausl.pr.it;

\section{Correspondence:}

Paolo Ossola,

Padiglione Braga \#21,

Azienda Ospedaliero-Universitaria di Parma,

via Antonio Gramsci, 14,

43126 Parma, Italy.

Tel. +390521903596 Fax. +390521396822

e-mail:paolo.ossola@unipr.it; ossola.paolo@gmail.com

\section{The study was conducted at}

Azienda Ospedaliero-Universitaria di Parma,

via Antonio Gramsci, 14,

43126 Parma, Italy.

Running Title: Anxiety, depression and MACE

Conflicts of interest: All authors declare no conflict of interest

Funding: This research did not receive any specific grant from funding agencies in the public, commercial, or not-for-profit sectors. 


\begin{abstract}
Objective. Depression is an established risk factor for Acute Coronary Syndrome (ACS) with an impact on cardiac prognosis, nonetheless the literature disagrees on the role played by anxiety. No study evaluated this relationship in a cardiac population with no history of depression and after their first ACS. The aim of this study is to explore these associations without the confounding role of long-lasting heart disease or psychiatric illnesses.
\end{abstract}

Methods. Two-hundred-sixty-six patients with no history of depression completed the Hospital Anxiety and Depression Scale and the PRIME-MD at baseline and at 1, 2, 4, 6, 9, 12 and 24 months follow-up after their first ACS. During the follow-up period, we collected information regarding the major adverse cardiac events.

Results. Developing a first-ever depressive episode, in a proportional hazard model, was associated with almost three times the risk of a recurrent cardiac event $(\mathrm{OR}=2.590$; $95 \% \mathrm{CI}=1.321,5.078 ; \mathrm{p}=.006)$. Furthermore, a moderation analysis revealed that increasing levels of baseline anxiety had opposing effects on cardiac outcomes, being protective only in those who did not develop incident depression $(B=-0.0824 ; 95 \% \mathrm{CI}=-0.164,-0.005 ; \mathrm{p}=.048)$. No dose-response effect between depressive or anxious symptoms and cardiac outcomes emerged.

Conclusion. Our results confirm the detrimental effect of depression on cardiac prognosis in a selected population and suggest that anxiety after the first ACS might have different roles depending on the illness' course.

Keywords: Acute Coronary Syndrome; Depressive Disorder; Readmission; Cardiac Death; Cohort Studies. 


\section{Introduction}

The detrimental effect of mental illnesses (Correll et al., 2017), and specifically, depression on cardiac outcome is well-established (Burg et al., 2013; Carney et al., 2003; Geulayov, Novikov, Dankner, \& Dankner, 2018; Meijer et al., 2013; Nicholson, Kuper, \& Hemingway, 2006). It remains unclear (Carney \& Freedland, 2012) as to what extent first-time incident depression, here defined as the first episode of depression, occurring after the onset of coronary disease in never depressed people, is particularly cardio-toxic (Goodman, Shimbo, Haas, Davidson, \& Rieckmann, 2008; Meyer, Hussein, Lange, \& Herrmann-Lingen, 2014; Osler et al., 2016; Surtess et al., 2008) or if a dose-response relationship between the depressive symptoms and cardiac outcome exists (Smolderen, Buchanan, et al., 2017).

It is possible that the studies supporting the latter hypothesis are biased by the effect of long lasting depressive and cardiac illnesses (Lespérance, Frasure-Smith, Talajic, \& Bourassa, 2002; Stenman, Holzmann, \& Sartipy, 2016). For example, evaluating subjects in the early stages of coronary disease, a recent study failed to find a correlation between depression and ACS severity (Pelletier et al., 2014), whereas, another (Yammine, Frazier, Padhye, Sanner, \& Burg, 2017) found that only previous but not current depressive symptoms predict subsequent major cardiac events.

Similarly, the role played by anxiety is still debated (Sokoreli, de Vries, Pauws, \& Steyerberg, 2016; Tully, Harrison, Cheung, \& Cosh, 2016). Some authors suggest that it increases the risk of adverse cardiac outcomes (de Jager et al., 2018; Van Beek et al., 2016), others finding that it exerts a protective effect on new cardiac events (Meyer, Hussein, Lange, \& HerrmannLingen, 2015) and yet another study, (Geulayov et al., 2018) not finding any effect on mortality. 
The aim of this study is to evaluate the role of incident depression in predicting recurrent cardiac events, within two years after the first ACS, in a population of never depressed subjects. This allows excluding the role of long-lasting illnesses and being more precise in defining a dose-response relationship between depression and cardiac outcome. We further try to clarify the role played by anxiety in predicting recurrent cardiac events by exploring the interaction between anxious and depressive symptoms measured repeatedly over the follow-up period.

\section{Method}

\subsection{Participants}

Patients consecutively admitted to the Coronary Intensive Care Unit of Parma from January 2009 to March 2012 for a first-ever ACS were included in the study. The study was fully explained and all the participants provided informed consent. The local ethics committee (Comitato Etico per Parma) approved the study protocol which was conducted according to the Declaration of Helsinki. Subjects were included in the study if (a) they presented symptoms suggestive of an acute coronary syndrome and for the first time: an ST-segment elevation myocardial infarction (STEMI); a non-ST-segment elevation myocardial infarction (NSTEMI); or unstable angina (Hamm et al., 2011; Van De Werf et al., 2008). The working diagnosis of NSTE-ACS was a rule-out diagnosis based on the ECG. Biomarkers (troponins) further distinguished NSTEMI and unstable angina (Hamm et al., 2011); (b) they had no history of major depression; (c) they did not satisfy the criteria for major depression at baseline; (c) they were over 18 years old; (d) they were proficient in Italian language; (e) they had no substance abuse or other dependencies; (f) they showed no cognitive impairment as demonstrated by a Mini Mental State Examination (MMSE) (Folstein, Folstein, \& McHugh, 1975) lower than 25; (f) they did not take any psychotropic medication. 
Subjects who did not complete all the evaluation or withdrew $(n=111)$ were excluded from the analyses. No difference in any of the socio-demographic variables emerged between the completers $(n=266)$ and those who dropped out.

\subsection{Data Collection}

At enrolment for each patient a GRACE score, which assesses mortality risk after acute coronary events (Eagle et al., 2004), was calculated. The Global Registry of Acute Coronary Events (GRACE) score considers age, history of MI, past or current congestive heart failure (CHF), heart rate, systolic blood pressure, serum creatinine, elevated cardiac enzymes, STsegment depression on ECG at admission, and in hospital percutaneous intervention.

Within three days of the acute coronary syndrome, socio-demographic variables were collected. All the subjects completed (a) the Primary Care Evaluation of Mental Disorder (PRIME-MD) to diagnose current or previous depressive episodes (Spitzer et al., 1994) followed by a psychiatric interview to confirm the diagnosis of a previous and current depressive episode, and (b) the Hospital Anxiety and Depression Scale (HADS) (Costantini et al., 1999; Zigmond \& Snaith, 1983).

Socio-demographic variables included gender, age, education (i.e. primary school from the ages of 5 through to 10 ; secondary from 11 to 14 ; high school from 15 to 19 ; and university for any graduated degree), marital status and working status (dichotomized into employed and unemployed; the latter including both students and retired). All subjects completed a form where we asked height, weight, alcohol consumption and whether they were smokers, we estimated the mean number of cigarettes smoked in a day.

The PRIME-MD is a structured interview, as opposed to the self-administered tool (PHQ-9), designed to diagnose mental disorder according to DSM-IV. The PRIME-MD evaluates the presence of nine depressive symptoms in the previous two weeks. Each symptom is rated on a four-point scale (from "not at all” to "most days"). The PRIME-MD has shown good specificity 
and sensitivity in detecting major depression in primary care (Spitzer, Kroenke, Williams, \& Group, 1999). A clinician-administered questionnaire would increase the specificity, given that the predictive value of self-administered questionnaires is generally low (Bunevicius, Staniute, Brozaitiene, \& Bunevicius, 2012).

HADS proved to be a good predictor of outcome in a cardiac population (Doyle, McGee, De La Harpe, Shelley, \& Conroy, 2006; Palacios, Khondoker, Achilla, Tylee, \& Hotopf, 2016), generating two subscale scores: the anxiety score (HADS-A) and the depression score (HADSD). Interestingly, the anxiety subscale of HADS is a combination of anxious arousal and negative affectivity according to the tripartite model of mood disorders (Dunbar, Ford, Hunt, $\&$ Der, 2000). As a result of this, the baseline anxiety seems to reflect general distress (Norton, Cosco, Doyle, Done, \& Sacker, 2013).

After inclusion in the study, patients were re-evaluated with the same questionnaires (i.e. HADS and PRIME-MD) one, two, four, six, nine, twelve and twenty-four months later. At each interval, the PRIME-MD was followed by a short interview performed by a psychiatrist, who verified if the answers were appropriate to the patients' condition. A patient was defined non-depressed if he/she did not satisfy the criteria (American Psychiatric Association, 2000) for major or minor depression at any evaluation during the follow-up period.

Information regarding the recurrent major adverse cardiovascular event (MACE) over the follow-up period was collected by the Coronary Intensive Care Unit I.T. registry and matched by phone calls to the participants in case the cardiac event was treated outside of the catchment area. MACE included (Panchal et al., 2014) ACS, non-elective revascularization, acute hospitalization because of post-ischemic heart failure or any death unless an unequivocal noncardiac cause could be established (Van Beek et al., 2016). Non-elective revascularizations during hospital admissions with other MACE diagnoses were not counted separately. We considered only spontaneous myocardial infarction rather than both spontaneous infarction and 
periprocedural infarction (Patti et al., 2011). Compared to the standard definition of MACE we excluded all-cause mortality and strokes because predictors might differ among these groups (Moise et al., 2018).

\subsection{Statistical Analyses}

MACE occurs in $15 \%$ of subjects in the two years after an acute coronary syndrome (Yammine et al., 2017) and depression in up to $20 \%$ of them (Thombs et al., 2006). We therefore estimated an initial population of 400 subjects so that, with a drop-out rate of $10 \%$ /year in a cardiac population (Worcester, Murphy, Mee, Roberts, \& Goble, 2004), would have resulted in approximately 300 subjects at follow-up with $45 \mathrm{MACE}$ and 60 depressive episodes. That would have been enough to run a regression analysis with up to four predictors as suggested by the study design (i.e. age, gender, depressive and anxious symptoms).

For anxiety and depression, we calculated the areas under the curve $\left(A U C_{A}\right.$ and $A U C_{D}$, respectively) with the trapezoid method and with the HADS anxiety and depression subscales. The rate of patients classified as with or without a recurrent MACE over the course of the follow-up were calculated. A Proportional Hazard Model (Cox regression, enter method) was used to evaluate which socio-demographic and clinical variables predicted the development of a MACE during the follow-up period. In the first block of the model we entered the age, which differed between the two groups (i.e. MACE vs no-MACE) and the GRACE score which is a validated predictor of outcome. In the second block we added the baseline scores at HADS (both the anxiety and depression subscale) as a measure of general distress or a transient reaction. In the third block the amount of anxiety and depression as two separate AUC at HADS, to evaluate the dose-response relationship. Lastly, we entered the development of a first-ever incident depressive episode as an independent variable in the fourth block. Significant multiplicative interactions between two independent variables resulting in the above additive model were further explored in moderation analyses (SPSS PROCESS macro, 
Model \#1) (Hayes, 2013). Collinearity among the parameters was explored. To compare the course of depression and anxiety over the follow-up period, we performed a repeated measure ANOVA with groups (depressed vs non-depressed; with vs without MACE) as a between subjects' factors.

\section{Results}

Two-hundred-sixty-six subjects completed all the evaluations in the second year after their first ACS. At baseline, three-hundred-and-four subjects completed all questionnaires. Data from the same sample or part of it (i.e. completers at 1 year follow-up) was published in previous papers aimed at evaluating the risk factors for the development of an incident depressive disorder (Marchesi et al., 2014b, 2014a, 2015; Ossola, Paglia, et al., 2015; Ossola, De Panfilis, Tonna, Ardissino, \& Marchesi, 2015). The patients' flowchart is detailed in Figure 1.

Figure 1. Patients' flow-chart

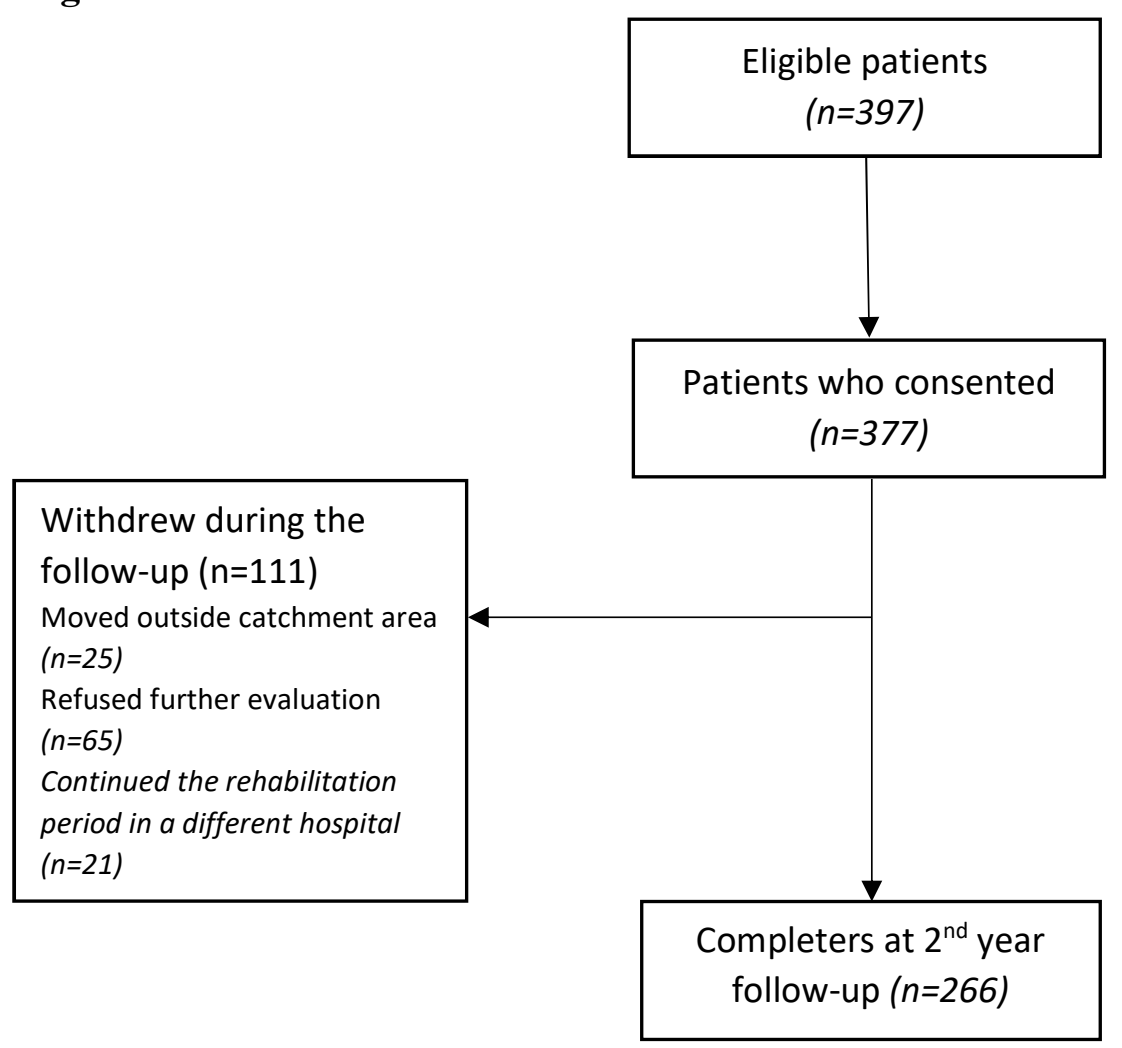

Throughout the follow-up period, $69(22.7 \%)$ of patients developed an incident depressive episode (Table 1). 
Table 1. Baseline characteristics of the completers $(n=266)$ with or without incident depression during the 2-year follow-up period

\begin{tabular}{|c|c|c|c|c|c|}
\hline & $\begin{array}{l}\text { Incident } \\
\text { Depression } \\
(\mathrm{n}=69)\end{array}$ & $\begin{array}{l}\text { Non- Incident } \\
\text { Depression } \\
(\mathrm{n}=197) \\
\end{array}$ & $\chi^{2}$ & t-test & $\mathrm{p}$ \\
\hline Male, $n(\%)$ & $49(71)$ & $168(85.3)$ & 6.91 & & $.009 * *$ \\
\hline Age, mean (s.d.) & $62.33(10.86)$ & $61.55(10.91)$ & & -.515 & .61 \\
\hline Education, $n(\%)$ & & & $1.55(3)$ & & .67 \\
\hline Primary school & $14(20.3)$ & $33(16.8)$ & & & \\
\hline Secondary school & $22(31.9)$ & $79(40.1)$ & & & \\
\hline High school & $28(40.6)$ & $71(36.0)$ & & & \\
\hline University & $5(7.2)$ & $14(7.1)$ & & & \\
\hline Marital status, $n(\%)$ & & & $7.58(3)$ & & $.006^{* *}$ \\
\hline Never married & $7(10.1)$ & $23(11.7)$ & & & \\
\hline Married & $45(65.2)$ & $152(77.2)$ & & & \\
\hline Separated/Divorced & $7(10.1)$ & $13(6.6)$ & & & \\
\hline Widowed & $10(14.5)$ & $9(4.6)$ & & & \\
\hline Unemployed, $n(\%)$ & $25(36.2)$ & $85(43.1)$ & 1.01 & & .31 \\
\hline Living Alone, $n(\%)$ & $18(26.1)$ & $26(13.2)$ & 6.14 & & .01 \\
\hline GRACE score, mean (s.d.) & $130.35(29.33)$ & $132.03(29.11)$ & & .41 & $.68^{*}$ \\
\hline Smokers, $n(\%)$ & $20(36.4)$ & $59(35.5)$ & .019 & & .89 \\
\hline Cigarettes/day, mean (s.d.) & $5.26(9.64)$ & $11.75(15.20)$ & & $\begin{array}{l}1.75 \\
(77)\end{array}$ & .08 \\
\hline
\end{tabular}




\begin{tabular}{lclcc}
\hline Alcohol glass/day, mean & & & & \\
(s.d.) & $0.48(.95)$ & $0.85(1.49)$ & 1.84 & .07 \\
BMI, mean (s.d.) & $26.27(3.31)$ & $27.61(4.19)$ & 1.84 & .07 \\
HADS at baseline, mean & & & & \\
(s.d.) & $9.46(4.48)$ & $8.63(5.42)$ & -1.14 & .25 \\
$\quad$ Anxiety & $8.34(4.03)$ & $6.17(4.03)$ & -3.84 & $<.001^{* * *}$ \\
Depression & & & & \\
AUC, mean (s.d.) & $101.98(41.28)$ & $87.57(53.59)$ & 1.95 & .06 \\
Anxiety & $93.96(39.67)$ & $71.11(41.36)$ & -3.82 & $<.001^{* * *}$ \\
Depression & & & & \\
\hline
\end{tabular}

Note. BMI, Body Mass Index; HADS, Hospital Anxiety and Depression Scale; AUC, Area under the Curve; ${ }^{*} \mathrm{p}<.05 ; * * \mathrm{p}<.01 ; * * * \mathrm{p}<.001 . \chi^{2}(\mathrm{df})=1$ and $\mathrm{t}$-test $(\mathrm{df})=264$ if not otherwise specified.

During the two years of follow-up, 57 subjects $(21.4 \%)$ developed at least one recurrent MACE. Among these, $\mathrm{n}=15(4.9 \%)$ were deaths. The only difference observed between patients with or without a recurrent MACE was age: patients who developed a MACE were slightly older $(\mathrm{d}=.45)$ (Table 2). In none of the included subjects did a new cardiac event precede the onset of the depressive episode.

Table 2. Baseline characteristics of the completers $(n=266)$ with or without recurrent MACE during the 2-year follow-up period

\begin{tabular}{llllll}
\hline & $\begin{array}{l}\text { MACE } \\
(\mathrm{n}=57)\end{array}$ & $\begin{array}{l}\text { No MACE } \\
(\mathrm{n}=209)\end{array}$ & $\chi^{2}$ & t-test & $\mathrm{p}$ \\
\hline Male, $n$ (\%) & $48(84.2)$ & $169(80.9)$ & .334 & .35 \\
Age, mean (s.d.) & $65.32(9.09)$ & $60.78(11.15)$ & & -2.83 & $.005^{* *}$ \\
Education, $n$ (\%) & & & $.773(3)$ & .83 \\
\hline
\end{tabular}




\begin{tabular}{|c|c|c|c|c|c|}
\hline Primary school & $12(21.1)$ & $35(16.7)$ & & & \\
\hline Secondary school & $22(38.6)$ & $79(37.8)$ & & & \\
\hline High school & $19(33.3)$ & $80(38.3)$ & & & \\
\hline University & $4(7.0)$ & $15(7.2)$ & & & \\
\hline Marital status, $n(\%)$ & & & $4.84(3)$ & & .19 \\
\hline Never married & $3(5.3)$ & $27(12.9)$ & & & \\
\hline Married & $47(82.5)$ & $150(71.8)$ & & & \\
\hline Separated/Divorced & $2(3.5)$ & $18(8.6)$ & & & \\
\hline Widowed & $5(8.8)$ & $14(6.7)$ & & & \\
\hline Unemployed, $n(\%)$ & $20(35.1)$ & $90(43.1)$ & 1.17 & & .17 \\
\hline Living Alone, $n(\%)$ & $16(38.1)$ & $90(43.1)$ & .030 & & .52 \\
\hline GRACE score, mean (s.d.) & $\begin{array}{l}129.79 \\
(27.55)\end{array}$ & $\begin{array}{l}132.09 \\
(29.59)\end{array}$ & & .527 & .59 \\
\hline Smokers, $n(\%)$ & $17(29.82)$ & $62(29.66)$ & .071 & & .86 \\
\hline Cigarettes/day, mean (s.d.) & $7.31(12.01)$ & $10.8(14.73)$ & & $.804(77)$ & .19 \\
\hline Alcohol glass/day, mean (s.d.) & $0.65(1.50)$ & $0.77(1.34)$ & & .556 & .57 \\
\hline BMI, mean (s.d.) & $27.27(4.08)$ & $27.28(4.04)$ & & .012 & .99 \\
\hline Incident Depression, $\mathrm{n}(\%)$ & $18(31.6)$ & $51(24.4)$ & 7.43 & & $.006^{* *}$ \\
\hline \multicolumn{6}{|l|}{ HADS at baseline, mean (s.d.) } \\
\hline Anxiety & $9.49(4.94)$ & $8.68(5.27)$ & & -1.00 & .29 \\
\hline Depression & $7.29(4.07)$ & $6.59(4.16)$ & & -1.10 & .25 \\
\hline \multicolumn{6}{|l|}{ AUC, mean (s.d.) } \\
\hline Anxiety & $80.9(49.3)$ & $95.15(51.5)$ & & 1.85 & .07 \\
\hline Depression & $73.17(44.9)$ & $80.17(42.4)$ & & 1.08 & .28 \\
\hline
\end{tabular}


Note. BMI, Body Mass Index; HADS, Hospital Anxiety and Depression Scale; AUC, Area under the Curve; ${ }^{*} \mathrm{p}<.05 ; * * \mathrm{p}<.01 ; * * * \mathrm{p}<.001 . \chi^{2}(\mathrm{df})=1$ and $\mathrm{t}$-test $(\mathrm{df})=264$ if not otherwise specified.

The development of a depressive episode during the follow-up period $\left(\mathrm{t}=0.740 ; \chi^{2}=5.465\right.$; $\mathrm{HR}=2.449 ; 95 \% \mathrm{CI}=1.26-4.75 ; \mathrm{p}=.008)$ was the only significant predictor of a recurrent MACE

\section{(Table 3).}

Table 3. Regression coefficients of the predictors of MACE (coded as 1) in a Cox-Regression with time to event.

\begin{tabular}{lcccc}
\hline & HR & $95 \%$ CI & $\chi^{2}$ & $\mathrm{p}$ \\
\hline Age & 1.028 & {$[.995,1.062]$} & 2.730 & .098 \\
GRACE score & .999 & {$[.987,1.011]$} & .022 & .883 \\
AUC & & & & \\
AUC & & & & \\
A & 1.009 & {$[.996,1.023]$} & 1.737 & .188 \\
HADS Depression & .923 & {$[.817,1.042]$} & 1.682 & .188 \\
HADS Anxiety & 1.034 & {$[.941,1.135]$} & .480 & .195 \\
Incident Depression & 2.590 & {$[1.321,5.078]$} & 7.673 & .006 \\
\hline
\end{tabular}

Note: CI, Confidence Interval; AUC= area under the curve; HADS, Hospital Anxiety and Depression Scale; $-2 * \log$ likelihood $=420.35 ; \chi^{2}(7)=17.31 ; p=.016$

In our sample baseline anxiety itself did not predict a recurrent MACE, however, we found a significant interaction $(\mathrm{HR}=1.081 ; 95 \% \mathrm{CI}=1.021-1.143 ; \mathrm{p}=.007)$ between incident depression and baseline HADS anxiety in predicting recurrent cardiac events. Specifically, controlling for age, gender and GRACE score, the effect of baseline anxiety on recurrent MACE was moderated by incident depression. According our model, baseline anxiety exerted a protective effect in those who did not develop a depressive episode $(B=-0.0824 ; 95 \% \mathrm{CI}=-0.164,-0.005$; 
$\mathrm{p}=.048$ ), whereas it increased, even though not significantly, the risk of a MACE in those who developed incident depression $(\mathrm{B}=0.077 ; 95 \% \mathrm{CI}=-0.05,0.213 ; \mathrm{p}=.26)$.

Is it possible that in non-depressed subjects, the protective effect of baseline anxiety on the recurrent MACE was explained by the lowering of its severity over the follow-up. Entering the HADS-A scores of the non-depressed subjects $(n=197)$ in a repeated measure ANOVA (Greenhouse-Geisser corrected, $\varepsilon=.44$ ) with time (the eight evaluations during the follow-up) and group (with and without MACE) revealed an effect of time $(\mathrm{F}(3.17,595.99)=4.6 ; \mathrm{p}=.03)$ but no interaction between time and group $(\mathrm{F}(3.17,595.99)=1.2 ; \mathrm{p}=.27)$. This suggests that, in non-depressed patients both with or without recurrent MACE, the levels of anxiety decreased over time but remained higher in subjetcs without a MACE throughout the follow-up period (Figure 2). Therefore those who did not develop a recurrent MACE were not anxious only immediately after the ACS and those who did develop a recurrent MACE were not simply more anxious during the follow-up.

Figure 2. Course of anxiety at HADS over the two-year follow up in the non-depressed group with (solid line, $\mathrm{n}=39$ ) and without (dotted line, $\mathrm{n}=158$ ) MACE.

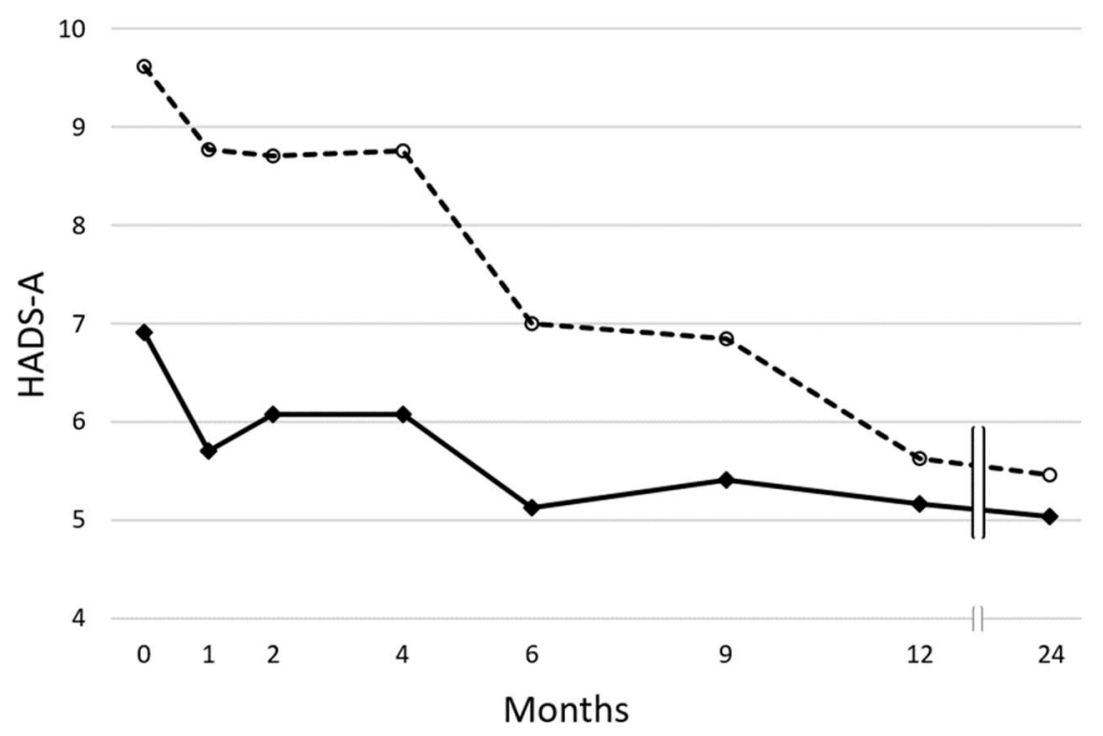


Note. HADS-A: Hospital and Depression Scale, Anxiety Subscale. Covariates at the following levels: Gender= .84; Age=61.80; GRACE-score=176.921

\section{Discussion}

This study evaluated in a sample of never depressed patients, at their first Acute Coronary Syndrome, the risk factors for the development of recurrent MACE within the two successive years.

Considering other clinical variables (i.e. baseline and cumulative scores at depression and anxiety) only age and incident depression were risk factors for the development of MACE, agreeing with the suggestion that incident depression (Keegan, Conroy, \& Doyle, 2016; May et al., 2017) has a cardio-toxic effect, particularly in the year following an ACS (Osler et al., 2016). We found no dose-response relationship (Brunner et al., 2014).

In suggesting a different approach to assess the effect of anxiety in coronary patients (Sokoreli et al., 2016) our results point out a possible interaction with depression. It is possible that increasing levels of baseline anxiety have a protective effect on cardiac outcome only in those who did not develop an incident depressive episode because of related healthy behaviours. Increased levels of anxiety may reflect the worry after the first ACS, which could induce a greater compliance with the medical prescription, promote adaptive coping strategies (Messerli-Bürgy et al., 2015) and healthy behaviours (Benyamini, Roziner, Goldbourt, Drory, \& Gerber, 2013; Gale et al., 2017). Alternatively an incident depressive episode could limit those healthy behaviours and the concomitant higher levels of anxiety might even bolster its cardio-toxic effect through an adrenergic stimulation (Meyer, Herrmann-Lingen, et al., 2015). The strict inclusion criteria (i.e. no history of or current depressive disorder and patients at their first ACS) and the long follow-up period resulted in a relatively small number of subjects who developed a depressive disorder and a recurrent MACE. This could have resulted in the nonsignificant effect of anxiety on recurrent MACE in this group. It is possible that, although all 
the MACE occurred after the depressive episodes, our results could underestimate the real interaction of depression and anxiety on cardiac outcome since those depressions with an onset in the second year may have not yet exerted their whole cardio-toxic effect.

Adopting the AUC as a method to assess the dose-response effect, we may have lost the suggested dichotomisation in transient and persistent depressive symptoms (Smolderen, Spertus, et al., 2017). Similarly, the inclusion of only those with no previous or current depressive episodes does not allow a direct comparison between first time and recurrent depression (Carney \& Freedland, 2012).

A possible limitation was excluding from the survival analysis the subjects who dropped out. When considering those who completed the questionnaires at baseline but dropped out during the follow-up $(\mathrm{n}=38)$ as censored results were substantially overlapping. The best predictor was still developing an incident depressive episode $(\mathrm{HR}=2.443 ; 95 \% \mathrm{CI}=1.257,4.747 ; \mathrm{p}=.008)$ but age remained a significant predictor $(\mathrm{HR}=1.042 ; 95 \% \mathrm{CI}=1.01,1.08 ; \mathrm{p}=.012)$. Similarly, the interaction with anxiety was still significant $(\mathrm{HR}=1.152 ; 95 \% \mathrm{CI}=1.004-1.322 ; \mathrm{p}=.044)$ and so was the moderation (non-depressed: $\mathrm{B}=-0.091 ; 95 \% \mathrm{CI}=-0.172,-0.010 ; \mathrm{p}=.027$; depressed: $\mathrm{B}=0.077 ; 95 \% \mathrm{CI}=-0.05,0.217 ; \mathrm{p}=.25)$.

\section{Conclusion}

Our results confirm the well-established detrimental effect of incident depression on cardiac prognosis (Frasure-Smith \& Lesperance, 2008; Yammine et al., 2017). We suggest that clinicians should both keep in mind the possible risk factors for its development (Ossola, Paglia, et al., 2015) and, given the associated burden (Szpakowski, Qiu, Masih, Kurdyak, \& Wijeysundera, 2017), treat the disorder (Gerra et al., 2014; Mavrides \& Nemeroff, 2013; Smolderen, Buchanan, et al., 2017) and the related conditions (Carney, Freedland, Steinmeyer, Rubin, \& Rich, 2016). Further, the present study proposes that anxious symptoms immediately after the first cardiac event could be an ally in preventing cardiac 
events in patients who do not develop incident depression.

\section{Acknowledgement:}

We would like to thank Dr Matteo Goldoni for the statistical support and Mr Alan McDonald for the language editing.

\section{References}

American Psychiatric Association. (2000). Diagnostic and statistical manual for mental disorder (DSM-IV-TR). Washington, DC:

Benyamini, Y., Roziner, I., Goldbourt, U., Drory, Y., \& Gerber, Y. (2013). Depression and anxiety following myocardial infarction and their inverse associations with future health behaviors and quality of life. Annals of Behavioral Medicine, 46(3), 310-321. https://doi.org/10.1007/s12160-013-9509-3

Brunner, E. J., Shipley, M. J., Britton, A. R., Stansfeld, S. a, Heuschmann, P. U., Rudd, A. G., ... Kivimaki, M. (2014). Depressive disorder, coronary heart disease, and stroke: dose-response and reverse causation effects in the Whitehall II cohort study. European Journal of Preventive Cardiology, 21(3), 340-6.

https://doi.org/10.1177/2047487314520785

Bunevicius, A., Staniute, M., Brozaitiene, J., \& Bunevicius, R. (2012). Diagnostic accuracy of self-rating scales for screening of depression in coronary artery disease patients. Journal of Psychosomatic Research, 72(1), 22-25. https://doi.org/10.1016/j.jpsychores.2011.10.006

Burg, M. M., Shimbo, D., Shaffer, J., Kronish, I. M., Whang, W., Alcántara, C., ... Muntner, P. (2013). The 'Perfect Storm' and Acute Coronary Syndrome Onset: Do Psychosocial Factors Play a Role? Progress in Cardiovascular Diseases, 55(6), 601-610. https://doi.org/10.1016/J.PCAD.2013.03.003

Carney, R. M., Blumenthal, J. A., Catellier, D., Freedland, K. E., Berkman, L. F., Watkins, L. 
L., ... Jaffe, A. S. (2003). Depression as a risk factor for mortality after acute myocardial infarction. The American Journal of Cardiology, 92(11), 1277-1281. https://doi.org/10.1016/J.AMJCARD.2003.08.007

Carney, R. M., \& Freedland, K. E. (2012). Is There a High-Risk Subtype of Depression in Patients with Coronary Heart Disease? Current Psychiatry Reports, 14(1), 1-7. https://doi.org/10.1007/s11920-011-0247-6

Carney, R. M., Freedland, K. E., Steinmeyer, B. C., Rubin, E. H., \& Rich, M. W. (2016). Clinical predictors of depression treatment outcomes in patients with coronary heart disease. Journal of Psychosomatic Research, 88, 36-41. https://doi.org/10.1016/j.jpsychores.2016.07.011

Correll, C. U., Solmi, M., Veronese, N., Bortolato, B., Rosson, S., Santonastaso, P., ... Stubbs, B. (2017). Prevalence, incidence and mortality from cardiovascular disease in patients with pooled and specific severe mental illness: a large-scale meta-analysis of 3,211,768 patients and 113,383,368 controls. World Psychiatry, 16(2), 163-180. https://doi.org/10.1002/wps.20420

Costantini, M., Musso, M., Viterbori, P., Bonci, F., Del Mastro, L., Garrone, O., ... Morasso, G. (1999). Detecting psychological distress in cancer patients: validity of the Italian version of the Hospital Anxiety and Depression Scale. Supportive Care in Cancer : Official Journal of the Multinational Association of Supportive Care in Cancer, 7(3), 121-7. https://doi.org/10.1007/s005209900026

de Jager, T. A. J., Dulfer, K., Radhoe, S., Bergmann, M. J., Daemen, J., van Domburg, R. T., ... Utens, E. M. W. J. (2018). Predictive value of depression and anxiety for long-term mortality: differences in outcome between acute coronary syndrome and stable angina pectoris. International Journal of Cardiology, 250, 43-48. https://doi.org/10.1016/j.ijcard.2017.10.005 
Doyle, F., McGee, H. M., De La Harpe, D., Shelley, E., \& Conroy, R. (2006). The Hospital Anxiety and Depression Scale depression subscale, but not the Beck Depression Inventory-Fast Scale, identifies patients with acute coronary syndrome at elevated risk of 1-year mortality. Journal of Psychosomatic Research, 60(5), 461-467. https://doi.org/10.1016/j.jpsychores.2005.09.004

Dunbar, M., Ford, G., Hunt, K., \& Der, G. (2000). A confirmatory factor analysis of the Hospital Anxiety and Depression scale: comparing empirically and theoretically derived structures. British Journal of Clinical, 39(1), 79-94.

Eagle, K. A., Lim, M. J., Dabbous, O. H., Pieper, K. S., Goldberg, R. J., Goodman, S. G., ... Fox, K. A. A. (2004). A Validated Prediction Model for All Forms of Acute Coronary Syndrome Estimating the Risk of 6-Month Postdischarge Death in an International Registry. JAMA, 291(22), 2727-2733.

Folstein, M. F., Folstein, S. E., \& McHugh, P. R. (1975). “Mini-mental state”. A practical method for grading the cognitive state of patients for the clinician. Journal of Psychiatric Research, 12(3), 189-198. https://doi.org/10.1016/0022-3956(75)90026-6

Frasure-Smith, N., \& Lesperance, F. (2008). Depression and anxiety as predictors of 2-year cardiac events in patients with stable coronary artery disease. JAMA Psychiatry, 65(1), 62-71. https://doi.org/10.1001/archgenpsychiatry.2007.4.

Gale, C. R., Čukić, I., Batty, G. D., McIntosh, A. M., Weiss, A., \& Deary, I. J. (2017). When Is Higher Neuroticism Protective Against Death? Findings From UK Biobank. Psychological Science, 28(9), 1345-1357. https://doi.org/10.1177/0956797617709813

Gerra, M. L., Marchesi, C., Amat, J. A., Blier, P., Hellerstein, D. J., \& Stewart, J. W. (2014). Does negative affectivity predict differential response to an SSRI versus a non-SSRI antidepressant? Journal of Clinical Psychiatry, 75(9), e939-e944. https://doi.org/10.4088/JCP.14m09025 
Geulayov, G., Novikov, I., Dankner, D., \& Dankner, R. (2018). Symptoms of depression and anxiety and 11-year all-cause mortality in men and women undergoing coronary artery bypass graft (CABG) surgery. Journal of Psychosomatic Research, 105, 106-114. https://doi.org/10.1016/J.JPSYCHORES.2017.11.017

Goodman, J., Shimbo, D., Haas, D. C., Davidson, K. W., \& Rieckmann, N. (2008). Incident and recurrent major depressive disorder and coronary artery disease severity in acute coronary syndrome patients. Journal of Psychiatric Research, 42(8), 670-675. https://doi.org/10.1016/J.JPSYCHIRES.2007.07.004

Hamm, C. W., Bassand, J.-P., Agewall, S., Bax, J., Boersma, E., Bueno, H., ... Widimsky, P. (2011). ESC Guidelines for the management of acute coronary syndromes in patients presenting without persistent ST-segment elevation: The Task Force for the management of acute coronary syndromes (ACS) in patients presenting without persistent ST-segment elevatio. European Heart Journal, 32(23), 2999-3054. https://doi.org/10.1093/eurheartj/ehr236

Hayes, A. (2013). Introduction to mediation, moderation, and conditional process analysis. New York, NY: Guilford. https://doi.org/978-1-60918-230-4

Keegan, C., Conroy, R., \& Doyle, F. (2016). Longitudinal modelling of theory-based depressive vulnerabilities, depression trajectories and poor outcomes post-ACS. Journal of Affective Disorders, 191, 41-48. https://doi.org/10.1016/j.jad.2015.11.030

Lespérance, F., Frasure-Smith, N., Talajic, M., \& Bourassa, M. G. (2002). Five-year risk of cardiac mortality in relation to initial severity and one-year changes in depression symptoms after myocardial infarction. Circulation, 105(9), 1049-1053. https://doi.org/10.1161/hc0902.104707

Marchesi, C., Ossola, P., Scagnelli, F., Mellini, L., Tonna, M., Ardissino, D., \& De Panfilis, C. (2015). The role of alexithymia in predicting incident depression in patients at first 
acute coronary syndrome. Comprehensive Psychiatry, 62, 86-92.

https://doi.org/10.1016/j.comppsych.2015.06.013

Marchesi, C., Ossola, P., Scagnelli, F., Paglia, F., Aprile, S., Monici, A., ... Ardissino, D. (2014a). Type D personality in never-depressed patients and the development of major and minor depression after acute coronary syndrome. Journal of Affective Disorders, 155, 194-199. https://doi.org/10.1016/j.jad.2013.10.052

Marchesi, C., Ossola, P., Scagnelli, F., Paglia, F., Aprile, S., Monici, A., ... Ardissino, D. (2014b). Type D personality in never depressed patients at their first acute coronary syndrome. Psychotherapy and Psychosomatics, 83(3), 190-191. https://doi.org/10.1159/000358525

Mavrides, N., \& Nemeroff, C. (2013). Treatment of depression in cardiovascular disease. Depression and Anxiety, 30(4), 328-341. https://doi.org/10.1002/da.22051

May, H. T., Horne, B. D., Knight, S., Knowlton, K. U., Bair, T. L., Lappé, D. L., ... Muhlestein, J. B. (2017). The association of depression at any time to the risk of death following coronary artery disease diagnosis. European Heart Journal - Quality of Care and Clinical Outcomes, 3(4), 296-302. https://doi.org/10.1093/ehjqcco/qcx017

Meijer, A., Conradi, H. J., Bos, E. H., Anselmino, M., Carney, R. M., Denollet, J., ... De Jonge, P. (2013). Adjusted prognostic association of depression following myocardial infarction with mortality and cardiovascular events: Individual patient data metaanalysis. British Journal of Psychiatry, 203(2), 90-102. https://doi.org/10.1192/bjp.bp.112.111195

Messerli-Bürgy, N., Molloy, G. J., Poole, L., Wikman, A., Carlos Kaski, J., \& Steptoe, A. (2015). Psychological coping and recurrent major adverse cardiac events following acute coronary syndrome. British Journal of Psychiatry, 207(3), 256-261. https://doi.org/10.1192/bjp.bp.114.154419 
Meyer, T., Herrmann-Lingen, C., Chavanon, M. L., Pieske, B., Wachter, R., \& Edelmann, F. (2015). Plasma mid-regional pro-adrenomedullin levels are inversely associated with anxiety but unrelated to depression: Results from the observational DIAST-CHF study in patients with cardiovascular risk factors. Psychoneuroendocrinology, 62, 227-232. https://doi.org/10.1016/j.psyneuen.2015.08.007

Meyer, T., Hussein, S., Lange, H. W., \& Herrmann-Lingen, C. (2014). Transient impact of baseline depression on mortality in patients with stable coronary heart disease during long-term follow-up. Clinical Research in Cardiology, 103(5), 389-395. https://doi.org/10.1007/s00392-014-0666-6

Meyer, T., Hussein, S., Lange, H. W., \& Herrmann-Lingen, C. (2015). Anxiety is associated with a reduction in both mortality and major adverse cardiovascular events five years after coronary stenting. European Journal of Preventive Cardiology, 22(1), 75-82. https://doi.org/10.1177/2047487313505244

Moise, N., Khodneva, Y., Jannat-Khah, D. P., Richman, J., Davidson, K. W., Kronish, I. M., ... Safford, M. M. (2018). Observational study of the differential impact of time-varying depressive symptoms on all-cause and cause-specific mortality by health status in community-dwelling adults: the REGARDS study. BMJ Open, 8(1), e017385. https://doi.org/10.1136/bmjopen-2017-017385

Nicholson, A., Kuper, H., \& Hemingway, H. (2006). Depression as an aetiologic and prognostic factor in coronary heart disease: a meta-analysis of 6362 events among 146 538 participants in 54 observational studies. European Heart Journal, 27(23), 27632774. https://doi.org/10.1093/eurheartj/ehl338

Norton, S., Cosco, T., Doyle, F., Done, J., \& Sacker, A. (2013). The Hospital Anxiety and Depression Scale: A meta confirmatory factor analysis. Journal of Psychosomatic Research, 74(1), 74-81. https://doi.org/10.1016/j.jpsychores.2012.10.010 
Osler, M., Mårtensson, S., Wium-Andersen, I. K., Prescott, E., Andersen, P. K., Jørgensen, T. S. H., ... Jørgensen, M. B. (2016). Depression After First Hospital Admission for Acute Coronary Syndrome: A Study of Time of Onset and Impact on Survival. American Journal of Epidemiology, 183(3), 218-26. https://doi.org/10.1093/aje/kwv227

Ossola, P., De Panfilis, C., Tonna, M., Ardissino, D., \& Marchesi, C. (2015). DS14 is more likely to measure depression rather than a personality disposition in patients with acute coronary syndrome. Scandinavian Journal of Psychology, 56(6), 685-692. https://doi.org/10.1111/sjop.12244

Ossola, P., Paglia, F., Pelosi, A., De Panfilis, C., Conte, G., Tonna, M., ... Marchesi, C. (2015). Risk factors for incident depression in patients at first acute coronary syndrome. Psychiatry Research, 228(3), 448-453. https://doi.org/10.1016/j.psychres.2015.05.063

Palacios, J. E., Khondoker, M., Achilla, E., Tylee, A., \& Hotopf, M. (2016). A Single, OneOff Measure of Depression and Anxiety Predicts Future Symptoms, Higher Healthcare Costs, and Lower Quality of Life in Coronary Heart Disease Patients: Analysis from a Multi-Wave, Primary Care Cohort Study. Plos One, 11(7), e0158163. https://doi.org/10.1371/journal.pone.0158163

Panchal, H. B., Ladia, V., Amin, P., Patel, P., Veeranki, S. P., Albalbissi, K., \& Paul, T. (2014). A meta-analysis of mortality and major adverse cardiovascular and cerebrovascular events in patients undergoing transfemoral versus transapical transcatheter aortic valve implantation using edwards valve for severe aortic stenosis. American Journal of Cardiology, 114(12), 1882-1890. https://doi.org/10.1016/j.amjcard.2014.09.029

Patti, G., Cannon, C. P., Murphy, S. A., Mega, S., Pasceri, V., Briguori, C., ... Di Sciascio, G. (2011). Clinical benefit of statin pretreatment in patients undergoing percutaneous coronary intervention: A collaborative patient-level meta-analysis of 13 randomized 
studies. Circulation, 123(15), 1622-1632.

https://doi.org/10.1161/CIRCULATIONAHA.110.002451

Pelletier, R., Lavoie, K. L., Bacon, S. L., Thanassoulis, G., Khan, N. A., Pilote, L., ...

Tagalakis, V. (2014). Depression and Disease Severity in Patients with Premature Acute Coronary Syndrome. The American Journal of Medicine, 127(1), 87-93.

https://doi.org/10.1016/J.AMJMED.2013.09.026

Smolderen, K. G., Buchanan, D. M., Gosch, K., Whooley, M., Chan, P. S., Vaccarino, V., ... Spertus, J. A. (2017). Depression Treatment and 1-Year Mortality after Acute Myocardial Infarction: Insights from the TRIUMPH Registry (Translational Research Investigating Underlying Disparities in Acute Myocardial Infarction Patients' Health Status). Circulation, 135(18), 1681-1689.

https://doi.org/10.1161/CIRCULATIONAHA.116.025140

Smolderen, K. G., Spertus, J. A., Gosch, K., Dreyer, R. P., D’Onofrio, G., Lichtman, J. H., ... Krumholz, H. M. (2017). Depression Treatment and Health Status Outcomes in Young Patients With Acute Myocardial Infarction. Circulation, 135(18), 1762-1764.

https://doi.org/10.1161/CIRCULATIONAHA.116.027042

Sokoreli, I., de Vries, J. J. G., Pauws, S. C., \& Steyerberg, E. W. (2016). Depression and anxiety as predictors of mortality among heart failure patients: systematic review and meta-analysis. Heart Failure Reviews, 21(1), 49-63. https://doi.org/10.1007/s10741$015-9517-4$

Spitzer, R. L., Kroenke, K., Williams, J. B. W., \& Group, and the P. H. Q. P. C. S. (1999). Validation and Utility of a Self-report Version of PRIME-MD The PHQ Primary Care Study. JAMA, 282(18), 1737-1744.

Spitzer, R. L., Williams, J. B. W., Kroenke, K., Linzer, M., Verloin deGruy Ill, F., Hahn, S. R., ... Johnson, J. G. (1994). Utility of a New Procedure for Diagnosing Mental 
Disorders in Primary Care. Jama, 272(22), 1749.

https://doi.org/10.1001/jama.1994.03520220043029

Stenman, M., Holzmann, M. J., \& Sartipy, U. (2016). Association between preoperative depression and long-term survival following coronary artery bypass surgery - A systematic review and meta-analysis. International Journal of Cardiology, 222, 462 466. https://doi.org/10.1016/j.ijcard.2016.07.216

Surtess, P. G., Wainwright, N. W. J., Luben, R. N., Wareham, N. J., Bingham, S. A., \& Khaw, K.-T. (2008). Depression and Ischemic Heart Disease Mortality: Evidence From the EPIC-Norfolk United Kingdom Prospective Cohort Study. American Journal of Psychiatry, 165(4), 515-523. https://doi.org/10.1176/appi.ajp.2007.07061018

Szpakowski, N., Qiu, F., Masih, S., Kurdyak, P., \& Wijeysundera, H. C. (2017). Economic impact of subsequent depression in patients with a new diagnosis of stable angina: A population-based study. Journal of the American Heart Association, 6(10), e006911. https://doi.org/10.1161/JAHA.117.006911

Tully, P. J., Harrison, N. J., Cheung, P., \& Cosh, S. (2016). Anxiety and Cardiovascular Disease Risk: a Review. Current Cardiology Reports, 18(12), 120. https://doi.org/10.1007/s11886-016-0800-3

Van Beek, M. H. C. T., Zuidersma, M., Lappenschaar, M., Pop, G., Roest, A. M., Van Balkom, A. J. L. M., ... Oude Voshaar, R. C. (2016). Prognostic association of cardiac anxiety with new cardiac events and mortality following myocardial infarction. British Journal of Psychiatry, 209(5), 400-406. https://doi.org/10.1192/bjp.bp.115174870

Van De Werf, F., Bax, J., Betriu, A., Blomstrom-Lundqvist, C., Crea, F., Falk, V., ... Rutten, F. (2008). Management of acute myocardial infarction in patients presenting with persistent ST-segment elevation. European Heart Journal, 29(23), 2909-2945. https://doi.org/10.1093/eurheartj/ehn416 
Worcester, M. U. C., Murphy, B. M., Mee, V. K., Roberts, S. B., \& Goble, A. J. (2004). Cardiac rehabilitation programmes: predictors of non-attendance and drop-out. European Journal of Cardiovascular Prevention \& Rehabilitation, 11(4), 328-335. https://doi.org/10.1097/01.hjr.0000137083.20844.54

Yammine, L., Frazier, L., Padhye, N. S., Sanner, J. E., \& Burg, M. M. (2017). Two-year prognosis after acute coronary syndrome in younger patients: Association with feeling depressed in the prior year, and BDI-II score and Endothelin-1. Journal of Psychosomatic Research, 99, 8-12. https://doi.org/10.1016/j.jpsychores.2017.05.017 Zigmond, A. S., \& Snaith, R. P. (1983). The Hospital Anxiety and Depression Scale. Acta Psychiatr Scand, 67(6), 361-370. https://doi.org/10.1111/j.1600-0447.1983.tb09716.x 